\title{
Influence of the Country's Information Level on Its Economic Development
}

\author{
Nataliia Gavkalova \\ dept. Public administration and \\ regeonal economy \\ Simon Kuznets Kharkiv National \\ University of Economics \\ Kharkiv, Ukraine \\ ngavl@ukr.net
}

\author{
Lola Yuliia Yuriivna * \\ dept. Public administration and \\ regeonal economy \\ Simon Kuznets Kharkiv National \\ University of Economics \\ Kharkiv, Ukraine \\ yuliia.lola@hneu.net \\ Mykhailenko Daria \\ dept. the Macroeconomic Analysis and \\ Forecasting Sector of the \\ Macroeconomic Policy and Regional \\ Development Department \\ the Research Center for Industrial \\ Development Problems of the National \\ Academy of Sciences \\ Kharkiv, Ukraine \\ mikhailenko.dg@gmail.com
}

\author{
Svitlana Prokopovych \\ dept. Economic Cybernetics \\ Simon Kuznets Kharkiv National \\ University of Economics \\ Kharkiv, Ukraine \\ prokopovichsv@gmail.com
}

\begin{abstract}
Information technologies forward and change all processes that are taking place in the modern society. Recent literature has been analysed as for the vector of information society development, influence of information technologies on development of business communications and social institutions. Asymmetry of information processes in the world has been analysed as well. The aim of this research is to study the moderated role of countries' IT level and its influence on social and economic development. The realised econometric research of the global indices (ICT, Doing Business, Global Competitiveness Index) for 113 countries of the world indicate different intensity of information and communication development influence in certain groups of countries (identified by the ICT level) on their economic level.
\end{abstract}

Keywords-economic development, the Information and Communication Development of a Country, the Doing Business, the Global Competitiveness Index, the correlation-regression analysis, clusters of countries.

\section{INTRODUCTION}

Informatisation of the society leads to changes in all spheres of a person's life. Transformations occur in interaction among the government, business and consumers, where the platform for interaction is now presented by computer network with the usage of artificial intelligence and robotic technology. Constant rapid implementation of modern technologies results in business digital transformation. It allows organising personalised interaction with clients that constitutes a permanent feature of the information society. Its consequences are fundamental changes in systems of management, corporate culture, and external communications of business structures. These processes are global and they overtake all countries of the world with different degree of intensity. However, on the other hand it results in enlarging the gap between countries in the level of using high technologies as well as fixing economic and social inequality.

\section{THEORETICAL DEVELOPMENT AND HYPOTHESES FORMULATION}

In the 20th century the most developed countries gradually entered the state of information society and it is expected that within a matter of a few decades the majority of the world's population will be living and working in a global information society [1].

Based on the analysis of social reality in the second half of the 20thcentury, socio-historical reasons of "knowledge" and "information" concepts confusion have been defined. The relations between confusing these concepts and the formation of knowledge society concepts and information society ones are shown [2].

New character of cognitive processes is caused by the new informative means which have appeared together with the Internet, e-mail and system of mass communication. They connected the world in uniform space [3].

The Global Brain proposes a positive vision for a more sustainable society. The Global Brain can be defined as the distributed intelligence emerging from all human and technological agents as interacting via the Internet. It plays the role of a nervous system for the social superorganism [4].

ICT carries the potential of opening economic opportunities, promoting social and political changes in society, providing access to knowledge, creating stimulus and a field for best practice sharing in all areas of life, the actual processes of informatisation across the globe are quite asymmetrical [5]. 
Contemporery enterprices can to improve the quality of information security solutions using structural analysis and design tools as CA AllFusion ERwin Data Modeler [6].

There is a close link between the level of information and communication development and the countries' tourist attractiveness. However, it is not equal for different countries, which are grouped by the level of intensity of tourism arrivals, the level of the country's attractiveness and its information and communication technologies development [7].

The research analysis of information technologies influence on the society structure challenges us to formulate new hypotheses and enlarge the research sphere.

Hypothesis 1. Information development of the society favours improvement of countries' economic attractiveness.

Hypothesis 2. Intensity of information development influence on economic level of countries is heterogeneous and can increase or decrease in various countries groups.

\section{METHODS}

In order to study the influence of the information and communication development of the country on the economic situation, the following algorithm of the research has been proposed:

Stage 1. Selection of the initial variables.

Stage 2. Research of the basic statistical characteristics of the selected variables.

Stage 3. Verification of the first hypothesis on the basis of the correlation-regression analysis methods.

Stage 4. Verification of the second hypothesis on the basis of the correlation-regression and cluster analysis methods for the whole array of initial data and within the scope of separate groups of countries, which are similar according to the level of economic and information development.

For implementation of the first stage of the algorithm, the following variables were selected: Information and Communication Technologies Development Index (ICT), Doing Business (DB) and Global Competitiveness Index (GCI).

To carry out the research, the global indices and variables of socio- political development were selected:

The Information and Communication Technologies Development Index (ICT) reflects the level of networked infrastructure and access to ICTs, the level of use of ICTs in the society and more efficient and effective ICT use [8]. This database was created ICT Data and Statistics Division Telecommunication Development Bureau International Telecommunication Union.

The Doing Business (DB) is reflected in simplicity of the entrepreneur activity and calculated in two stages: by analysing normative legal acts and by interviewing entrepreneurs. These regulations are measured using indicator sets: starting a business, dealing with construction permits, getting electricity, registering property, getting credit, protecting minority investors, paying taxes, trading across borders, enforcing contracts, resolving insolvency and labor market regulation[9]. The rating of countries is calculated by the World Bank.

The Global Competitiveness Index (GCI) shows the ability of countries to provide a high level of welfare to their citizens. It combines 114 indicators that capture concepts that matter for productivity and long-term prosperity. These indicators are grouped into 12 pillars: institutions, infrastructure, macroeconomic environment, health and primary education, higher education and training, goods market efficiency, labor market efficiency, financial market development, technological readiness, market size, business sophistication, and innovation [10]. The country's rating is calculated by the World Economic Forum.

The objects of research are 113 countries of the world. The variables are the data for 2017. The countries without sufficient data were excluded from the database.

\section{RESULTS}

The descriptive statistics was used to process, systematize and provide quantitative description of the empirical data by means of the main statistical indicators. The implementation of the second stage of the study presupposed the calculation of the following characteristics: Mean, Median, Mode, Frequency of Mode, Minimum, Maximum, Variance, Standard Deviation, Coefficient of Variation, Skewness, Kurtosis, as well as histograming. The results of calculation are presented in Table.I.

TABLE I. DESCRIPTIVE STATISTICS T

\begin{tabular}{|c|c|c|c|c|c|c|c|c|c|c|}
\hline \multirow[b]{2}{*}{$\begin{array}{l}\stackrel{0}{0} \\
\frac{\pi}{\pi} \\
\frac{\pi}{\pi}\end{array}$} & \multicolumn{10}{|c|}{ Descriptive Statistics } \\
\hline & $\stackrel{\Xi}{\Xi}$ &  & $\stackrel{\Xi}{\Xi}$ & $\Xi$ & $\breve{\Xi}$ & క & $\ddot{\nabla}$ & ¿ & $\begin{array}{c}\frac{\dot{\Sigma}}{\bar{v}} \\
\tilde{\omega}\end{array}$ & $\dot{s}$ \\
\hline GCI & 4,35 & 4,29 & 3,91 & 2,89 & 5,86 & 0,482 & \begin{tabular}{|l|l|} 
\\
\end{tabular} & 15,9 & 0,24 & $-0,4$ \\
\hline DB & 66,4 & 68,02 & 78,73 & 38,3 & 86,55 & 128,39 & 11,3 & 17,06 & $-0,38$ & $-0,77$ \\
\hline ICT & 5,46 & 5,76 & 4,67 & 1,27 & 8,98 & 4,89 & 2,21 & 40,55 & $-0,26$ & $-1,18$ \\
\hline
\end{tabular}

According to the results of the analysis of the obtained statistical characteristics and distribution histograms, the following conclusions can be made:

- the Global Competitiveness variable has a distribution close to normal. This is evidenced by the proximity of the mean, mode and median, as well as small values of the skewness and kurtosis. This variable has the least value of the coefficient of variation $(15,98)$;

- the Doing Business variable also has a distribution rather close to normal. Its average number is also close to the median one, but it has a little bigger variation coefficient (17.06). Unlike two other indices, it has another dimension that leads to a bigger spread (from 38.3 to 86.55). An insignificant left-side displacement is seen for DB index;

- insignificant left-side displacement (asymmetry coefficient is equal to -0,26) and insignificant low-topping (kurtosis coefficient is equal to -1,1822) are typical for disposal of this index. In 2016 this index had a significant spread (from 1,27 to 8,98), the value of this index in more than 50 countries differ from 6 to 9 , that is nearly half of the researched countries of the world get into the last three intervals. It proves that nearly $50 \%$ of countries with a high level of information development got into the option list. 
The first hypothesis, that states: information development of the society favours improvement of countries' economic development, has been verified during realisation of the third stage of the experiment. A pair correlation coefficient among the Global Competitiveness Index (GCI), the Doing Business (DB)and ICT variables has been calculated according to the data from all 113 countries: $r_{G C, I C T}=0,851, \quad r_{D B, I C T}=0,844$. Such high values allow confirming that there is quite a close direct linear connection between GC and ICT as well as between DB and ICT.

To study the effect of ICT on GC and DB, we construct a complex regression:

$$
\left\{\begin{array}{l}
\overline{G C}=a_{10}+a_{11} \cdot I C T, \\
\overrightarrow{D B}=a_{20}+a_{21} \cdot I C T,
\end{array}\right.
$$

Where $a_{i j}$ - unknown parameters that are estimated with the help of ordinary least squares method (OLS).

The relationship between the considered parameters is presented in Fig.1-2.

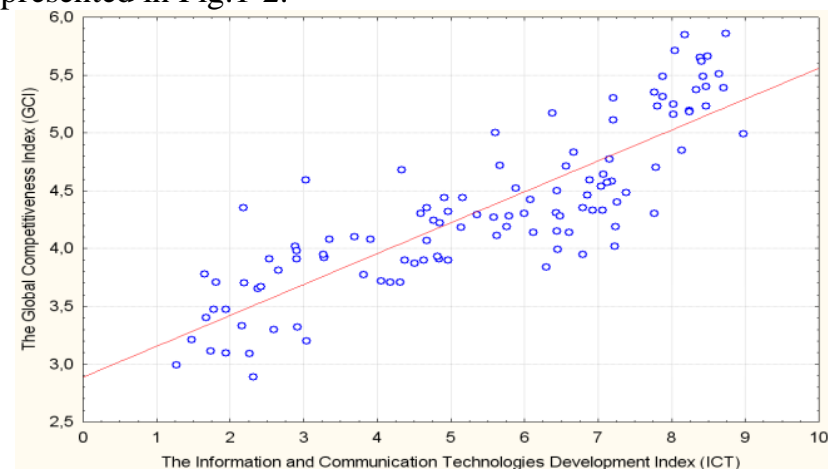

Fig. 1. Scatterplot GCI and ICT

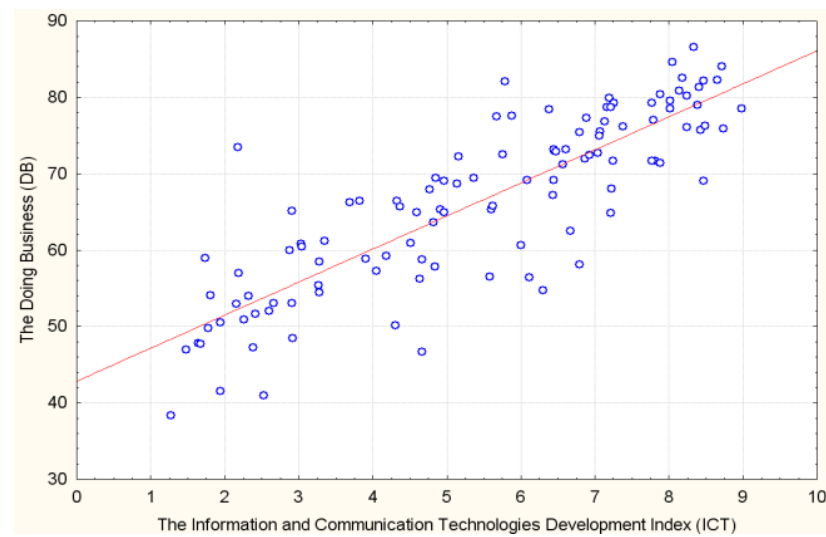

Fig. 2. Scatterplot DB and ICT

Realisation of this model has been held with the help of STATISTICA package by gradual usage of OLS to each equation. The following results have been obtained:

$$
\left\{\begin{array}{l}
\widehat{G C}=2.8878+0.2672 \cdot I C T, \\
\widetilde{D B}=41.8359+4.3252 \cdot I C T,
\end{array}\right.
$$

The data of regression equations are statistically significant on the whole by Fisher criterion $\left(F_{G C I}(1 ; 111)=291.936, \quad F_{D B}(1 ; 111)=275.829\right)$, and by certain parameters by Student's criterion $\left(t_{a 10}=31.38\right.$, $\left.t_{a 11}=17.09, t_{a 20}=27.96, t_{a 21}=16.61\right)$. The coefficients of multiple correlation $\quad\left(R_{G C I}=0.851, \quad R_{D B}=0.844\right)$, determination $\left(R_{G C I}^{2}=0.725, R_{D B}^{2}=0.713\right)$ and corrected determination coefficient $\left(R^{2}{ }_{a d j G C I}=0.722, R^{2}{ }_{a d j D B}=0.71\right)$ prove high quality of the model. There is no autocorrelation of mistakes (statistics of Darbin-Watson approximately equals to 2, and cyclic coefficient of autocorrelation is rough 0 ). So we draw a conclusion that the given model can be used for analysis.

It can be noted that increase in ICT by one, will provoke increase in the Global Competitiveness Index approximately by 0.2672 , and the Doing Business index - by 4.3252 unities. This influence is direct and statistically significant.

Thus, hypothesis 1 is proved.

Realisation of the fourth stage presupposes verification of the second hypothesis that states: intensity of information development effect on economic development of countries is heterogeneous and can increase or decrease in various countries groups.

The following stages are proposed to verify this hypothesis:

Stage 1. Countries disposal into homogeneous groups by values of indices the Global Competitiveness Index, the Doing Business index and ICT based on cluster analysis methods.

Stage 2. Construction of complex regression of the kind (1) for each of the clusters.

Stage 3. Making conclusions.

At the first stage with the help of cluster analysis methods, we obtain homogeneous countries groups. The countries can be quite clearly allocated into two or three clusters based on Word hierarchical method.

Allocation into 2 clusters will be little informative. That is why, to our mind, it is expedient to allocate countries into three clusters that corresponds to content allocation into countries with a high, middle and low level of economic and information development.

The following results of cauterisation have been obtained based on clusterisation iteration k-mean method.

Members of cluster number 1 and distances from respective cluster center are listed in Table II.

TABLE II. MEMBERS OF CLUSTER NUMBER 1

\begin{tabular}{|l|c|l|r|l|c|}
\hline Country & Distance & Country & Distance & Country & Distance \\
\hline Algeria & 4,09 & Ethiopia & 3,52 & Mauritania & 1,74 \\
\hline Angola & 7,07 & Ghana & 2,12 & Mozambique & 0,77 \\
\hline Argentina & 3,28 & Guatemala & 4,36 & Nepal & 3,65 \\
\hline Bangladesh & 7,32 & Guinea & 2,39 & Nicaragua & 1,02 \\
\hline Benin & 2 & Honduras & 2,78 & Nigeria & 1,04 \\
\hline Bolivia & 2,08 & India & 4,14 & Pakistan & 1,26 \\
\hline Brazil & 2,31 & Iran (I.R.) & 2,13 & Paraguay & 3,24 \\
\hline Burundi & 4,03 & Jordan & 4,31 & Philippines & 3,07 \\
\hline Cambodia & 0,49 & Lao P.D.R. & 0,44 & Senegal & 0,5 \\
\hline Cameroon & 3,74 & Lebanon & 1,83 & Sri Lanka & 3,04 \\
\hline Chad & 8,95 & Lesotho & 3,93 & Tanzania & 0,89 \\
\hline Dominican R. & 4,27 & Madagascar & 3,58 & Uganda & 2,01 \\
\hline Ecuador & 2,58 & Malawi & 3,21 & Zimbabwe & \multirow{2}{*}{3} \\
\hline Egypt & 1,68 & Mali & 0,81 & & \\
\hline
\end{tabular}


Based on the iterative method of clustering k-means, the following cluster results have been obtained. The first cluster includes 41 countries with the low level of economic and information development (Cluster contains 41 cases).

The second cluster includes 38 countries with an average level of economic and information development (Cluster contains 38 cases) and is presented in Table III.

TABLE III. MEMBERS OF CLUSTER NUMBER 2

\begin{tabular}{|l|c|l|c|l|c|}
\hline \multicolumn{1}{|c|}{ Country } & Distance & Country & Distance & Country & Distance \\
\hline Albania & 0,42 & Greece & 1 & Oman & 1,06 \\
\hline Armenia & 2,07 & Hungary & 2,1 & Panama & 2,17 \\
\hline Belgium & 2,03 & Indonesia & 1,66 & Peru & 0,63 \\
\hline Bhutan & 1,96 & Israel & 1,95 & Qatar & 2,52 \\
\hline Botswana & 2,40 & Italy & 2,3 & Romania & 2,31 \\
\hline Bulgaria & 1,83 & Kenya & 2,75 & Rwanda & 3,32 \\
\hline Chile & 1,41 & Kyrgyzstan & 2,05 & S. Arabia & 3,75 \\
\hline China & 2,13 & Luxembourg & 1,62 & Serbia & 2,48 \\
\hline Colombia & 0,38 & Mexico & 1,97 & S. Africa & 2,38 \\
\hline Costa Rica & 0,39 & Mongolia & 0,56 & Tunisia & 3,15 \\
\hline Croatia & 1,81 & Moldova & 2,39 & Turkey & 0,21 \\
\hline Cyprus & 1,93 & Montenegro & 2,49 & \multirow{2}{*}{ Ukraine } & \multirow{2}{*}{1,84} \\
\hline El Salvador & 1,88 & Morocco & 0,84 & & \\
\hline
\end{tabular}

The third cluster includes 34 countries with the highest level of economic and information development (Cluster contains 34 cases). Members of cluster number 3 and distances from respective cluster center are presented in Table IV.

TABLE IV. MEMBERS OF CLUSTER NUMBER 3

\begin{tabular}{|l|c|l|c|l|c|}
\hline $\begin{array}{c}\text { Countr } \\
\mathbf{y}\end{array}$ & Distance & Country & Distance & Country & Distance \\
\hline Australia & 0,70 & Ireland & 0,33 & Portugal & 1,36 \\
\hline Austria & 0,38 & Japan & 2,02 & Russian F. & 2,11 \\
\hline Canada & 0,21 & Kazakhstan & 2,20 & Singapore & 3,20 \\
\hline Czech Rep & 0,40 & Latvia & 0,47 & Slovakia & 2,47 \\
\hline Denmark & 2,95 & Lithuania & 0,61 & Slovenia & 1,74 \\
\hline Estonia & 1,04 & Malaysia & 0,84 & Spain & 1,21 \\
\hline Finland & 0,79 & Mauritius & 1,40 & Sweden & 1,37 \\
\hline France & 1,79 & Netherlands & 1,72 & Switzerland & 1,98 \\
\hline Georgia & 2,08 & New Zealand & 4,34 & Thailand & 1,51 \\
\hline Germany & 0,54 & Norway & 1,85 & UAE & 0,36 \\
\hline Iceland & \multirow{2}{*}{0,83} & Poland & \multirow{2}{*}{1,15} & UK & 1,92 \\
\cline { 5 - 6 } & & & US & 2,07 \\
\hline
\end{tabular}

It should be noted that the obtained grouping of countries according to the level of economic and information development is steady as the hierarchical method of full connection and the k-mean method have given the same results except the country numbered 78 (Uruguay), which was allocated to the countries with a low development level according to the first method, and to the countries with a middle development level according to the second level. We take that result for the final one which is given by the k-mean method, as this method minimises the internal group dispersion and maximises the intra-group, providing in such a way cauterisation of higher quality.

Analysis of the means allows to draw the following conclusions.
Firstly, cluster number 1 is formed from countries with the lowest values of indices The Information and Communication Technologies Development Index (ICT), the Global Competitiveness Index (GCI) and DB. The second cluster is constituted by countries with a middle level of ICT, GCI and DB. The third cluster comprises countries with the highest level of ICT, GCI and DB.

At the second stage of the proposed algorithm we build complex regression of the kind (1) and get the following results.

For cluster 1 (with a low level of development):

$$
\left\{\begin{array}{l}
\widehat{G C I}=3,1445+0,1729 \cdot I C T, \\
\widehat{D B}=47,0591+1,9949 \cdot I C T,
\end{array}\right.
$$

The data of the regression equation are statistically significant overall by Fisher criterion $\left(F_{G C I}(1 ; 39)=25.542\right.$, $\left.F_{D B}(1 ; 39)=13.194\right)$, and by certain parameters by Student criterion $\left(t_{a 10}=21.51, t_{a 11}=5.05, t_{a 20}=23.78, t_{a 21}=3.68\right)$, Coefficients of multiple correlation $\left(R_{G C I}=0.629\right.$, $\left.R_{D B}=0.503\right)$, determination $\left(R_{G C I}^{2}=0.396, R_{D B}^{2}=0.253\right)$ and corrected determination coefficients $\left(R^{2}{ }_{\text {adjGCI }}=0.382\right.$, $\left.R^{2}{ }_{a d j D B}=0.234\right)$ indicate not quite high quality of the model.

For cluster 2 (with a middle level of development):

$$
\left\{\begin{array}{l}
\widetilde{G C} I=3,5429+0,1441 \times I C T, \\
\overrightarrow{D B}=64,1988+0,8146 \times I C T,
\end{array}\right.
$$

The data of regression equation are statistically significant overall by Fisher criterion $\left(F_{G C I}(1 ; 36)=13.878\right.$, $\left.F_{D B}(1 ; 36)=5.357\right)$, and by certain parameters by Student criterion $\left(t_{a 10}=15.35, \quad t_{a 11}=3.73, t_{a 20}=30.56, \quad t_{a 21}=2.31\right)$. Coefficients of multiple correlation $\left(R_{G C I}=0.527\right.$, $\left.R_{D B}=0.36\right)$, determination $\left(R_{G C I}^{2}=0.278, R_{D B}^{2}=0.13\right)$ and corrected determination coefficients $\left(R^{2}{ }_{a d j G C I}=0.258\right.$, $\left.R^{2}{ }_{a d j D B}=0.105\right)$ indicate the model quality which is a little lower than for the model (3)

For cluster 3 (with a high level of development):

$$
\left\{\begin{array}{l}
G C I=2.0235+0.3971 \cdot I C T \\
\widehat{B D}=71.8186+0.9462 \cdot I C T
\end{array}\right.
$$

By Fisher criterion only the equation for GC $\left(F_{G C I}(1 ; 32)=34.617\right)$ is statistically significant overall, while for DB $F_{D B}(1 ; 32)=2.95$, aSignificance $F=0.0955$. By Student criterion the significant parameters are $a_{10}, a_{11}$, та $a_{20}, \quad\left(t_{a 10}=3.88, \quad t_{a 11}=5.88, \quad t_{a 20}=16.89\right), \quad$ while the parameter $\mathrm{a}_{21}$ is statistically insignificant $\left(t_{a 21}=1.72\right.$, $\mathrm{P}$ value $=0,0955)$. Coefficients of multiple correlation $\left(R_{G C I}=0.721, \quad R_{D B}=0.291\right)$, determination $\quad\left(R_{G C I}^{2}=0.52\right.$, $\left.R_{D B}^{2}=0.084\right)$ and corrected determination coefficients $\left(R^{2} a d j G C I=0.505, R_{a d j D B}^{2}=0.056\right)$ differ significantly for these two equations that indicates quite high quality of GC model and low model quality for DB.

Let us analyse values of regression coefficients in models (2) - (5) that are given in Table $\mathrm{V}$ in order to research the changes in influence of ICT on GCI and DB in each cluster. 
TABLE V. REGRESSION COEFFICIENTS

\begin{tabular}{|c|c|c|c|c|c|}
\hline Model & Coef. & Total & Claster 1 & Claster 2 & Claster 3 \\
\hline \multirow{2}{*}{ GCI } & $a_{10}$ & 2,8878 & 3,1445 & 3,5429 & 2,0235 \\
\cline { 2 - 6 } & $a_{11}$ & 0,2672 & 0,1729 & 0,1441 & 0,3971 \\
\hline \multirow{2}{*}{ DB } & $a_{20}$ & 42,835 & 47,0591 & 64,199 & 71,818 \\
\cline { 2 - 6 } & $a_{21}$ & 4,3252 & 1,9949 & 0,8146 & 0,9462 \\
\hline
\end{tabular}

As we can see from Table $\mathrm{V}$ a higher value of Intercept $\left(a_{10}\right)$ is characteristic for cluster 1 by the GCI index in comparison with the whole set of data, but a little lower of the value of the slope angle $\left(a_{11}\right)$ of the regression line. Cluster 2 is characterised by the highest value of Intercept $\left(a_{10}\right)$, and the lowest value of $a_{11}$ in comparison with other clusters and the whole option. Cluster 3 is characterised by the lowest value of Intercept $\left(a_{10}\right)$, but the highest value of the slope angle $\left(a_{11}\right)$ of the regression line. It means that the speed of GCI reaction to ICT increase will be the lowest for cluster 2 , and the highest for cluster 3 .

The situation is similar with DB index. The change speed of DB index under the influence of ICT is the lowest for countries from cluster 2 and the highest for countries with a low level of economic development. But «the starting conditions», that is the coefficient value $a_{20}$, are much higher for clusters 2 and 3 .

Thus, on the basis of the aforementioned, the hypothesis 2 is accepted.

Further researches are aimed at studying the stability of the identified dependencies over time.

\section{DISCUSSION AND CONCLUSION}

So, the influence of information and communication factor on their economic development is analysed on the basis of the global indices ICT, GC and DB. The correlation and regression analysis has shown a close connection among these indices. Further research of this connection in groups of countries identified by ICT level has indicated that the largest connection is seen in countries with a high ICT level. That is increase in its level gives the fastest and the biggest effect in highly developed countries. It is interesting that such effect is the most slowed in the group of countries with a middle ICT, GCI and DB level. It gives grounds to confirm and enlarge conclusions of B. R. Schlichter, L. Danylchenko, concerning the increase in social and economic gap among countries due to development of information technologies. That is why governments of countries have to correct the strategic vector of countries development taking into account the analysed tendencies.

\section{REFERENCES}

[1] L. Karvalics, Information Society Dimensions, Szeged: JATEPress Kiadó, 2009.

[2] A. O. Karpov, "The problem of separating the notions of "knowledge" and "information" in the knowledge society and its education," in Proc. 7th International Conference on Intercultural Education Education, Health and ICT for a Transcultural World, Almeria, 2016, pp. 804-810.

[3] N. Pogukaeva, "Cognitive management in the information society context," Procedia - Social and Behavioral Sciences, Vol. 166, pp. 456-459, 2015.

doi:10.1016/j.sbspro.2017.02.152

[4] F. Heylighen, and M. Marta, Lenartowicz, "The Global Brain as a model of the future information society: An introduction to the special issue," Technological Forecasting and Social Change, no 114, pp. 16, January 2017. doi:10.1016/j.techfore.2016.10.063

[5] B. R. Schlichter, and L. Danylchenko, "Measuring ICT usage quality for information society building," Government Information Quarterly, no 31(1), pp. 170-184, January 2013.

[6] L. Chagovets, S. Prokopovych, and V.Chahovets, "Estimation of Structural-Topological Characteristics in Information Security System," Problems of Infocommunications. Science and Technology, Kharkiv, 2018, pp.265-270.

[7] Y. Lola, S. Prokopovich, and O. Akhmedova, "Influence of the country's information development on its tourist attractiveness," CEUR Workshop Proceedings, Vol. 2393, pp. 450-464, June 2019.

[8] The ICT Development Index, 2017. [Online]. Available: https://www.itu.int/net4/ITU-D/idi/2017/index.html\#idi 2017 ranktab.Accessed on: May 30, 2019.

[9] The Doing Business Report, 2017. [Online]. Available: http://www.doingbusiness.org/reports/global-reports/doing-business2017. Accessed on: May 30, 2019

[10] The Global Competitiveness Report, 2016-2017. [Online]. Available: https://www.weforum.org/reports/the-global-competitiveness-report2016-2017-1. Accessed on: May 30, 2019. 